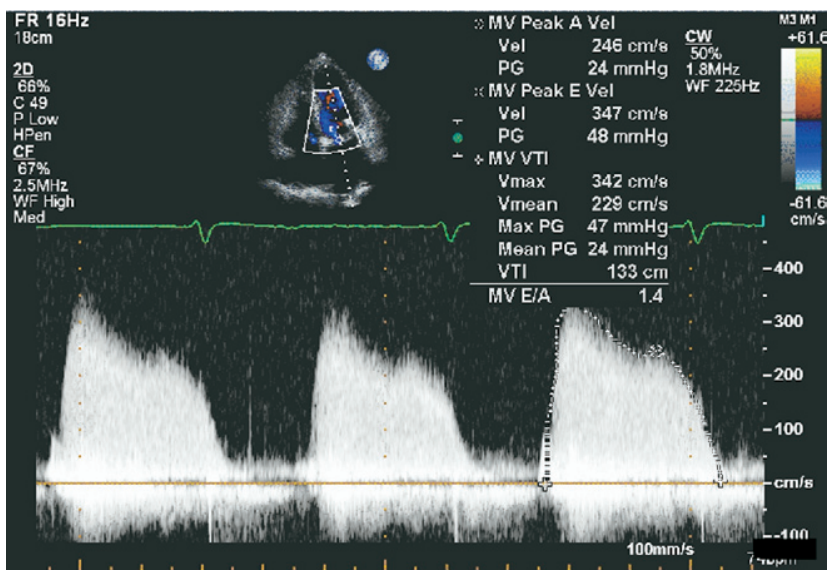

Figure 2. Doppler scan showing increased mean mitral pressure gradient (mean mitral pressure gradient $24 \mathrm{~mm} \mathrm{Hg}$ ).

bioprosthetic valve implantation in the mitral position. ${ }^{1}$ Radiofrequency maze lesion lines were unlikely to be a source leading to propagation onto the valve leaflets because there were no intraatrial clots and thrombus was laminar along all the valve leaflets.

Intravenous heparin was started in this patient with a plan to commence thrombolytic therapy if heparin alone was ineffective. Although thrombolytic therapy is an established first-line treat- ment, this patient responded to heparin anticoagulation followed by warfarin. Several studies have reported good resolution of bioprosthetic thrombus after conventional anticoagulation. ${ }^{2-5}$ Concurring with these studies, we had a favorable result after 1 week of heparin and subsequent warfarinization.

Clinically significant bioprosthetic valve thrombosis is rare, although the reported incidence in the study by Oliver and colleagues ${ }^{5}$ is $6.2 \%$. It should be considered a possible cause of valve dysfunction when there is increasing transvalvular pressure gradient after anticoagulation is terminated. Treatment with conventional anticoagulation is unavoidable in such a setting.

\section{References}

1. Stein PD, Alpert JS, Dalen JE, Horstkotte D, Turpie AG. Antithrombotic therapy in patients with mechanical and biological prosthetic heart valves. Chest. 1998;114(suppl 5):602S-10S.

2. Thomas B, Carreras F, Borras X, Pons-Lladó G. An usual case of bioprosthetic mitral valve thrombosis. Ann Thorac Surg. 2001;72: 259-61.

3. Korkolis DP, Passik CS, Marshalko SJ, Koullias GJ. Early bioprosthetic mitral valve "pseudostenosis" after complete preservation of the native mitral apparatus. Ann Thorac Surg. 2002;74:1689-91.

4. Koppensteiner R, Moritz A, Schlick W, et al. Blood rheology after cardiac valve replacement with mechanical prostheses or bioprostheses. Am J Cardiol. 1991;67:79-83.

5. Oliver JM, Galloge P, Gonzalez A, Dominguez FJ, Gamallo C, Mesa JM. Bioprosthetic mitral valve thrombosis: clinical profile, transesophageal echocardiographic features, and follow-up after anticoagulant therapy. J Am Soc Echocardiogr. 1996;9:691-9.

\title{
A case of mitral valve plasty for Libman-Sacks endocarditis mimicking a cardiac tumor
}

Shingo Taguchi, MD, Kazuhiro Hashimoto, MD, Yoshimasa Sakamoto, MD, Hiroshi Okuyama, MD, and Shinichi Ishii, MD, Tokyo, Japan

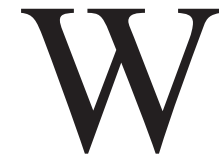
e report a patient with multiple cerebral infarcts in whom 2-dimensional echocardiography showed a large mass attached to the anterior mitral leaflet and chordae. An intracardiac tumor was diagnosed, and surgical intervention was performed. The resected mass

\footnotetext{
From the Department of Cardiovascular Surgery, Jikei University School of Medicine, Tokyo, Japan.

Received for publication May 27, 2006; revisions received June 27, 2006; accepted for publication July 12, 2006.

Address for reprints: Kazuhiro Hashimoto, MD, Department of Cardiovascular Surgery, Jikei University School of Medicine, 3-25-8, Nishishinbashi, Minato-ku, Tokyo, Japan, 105-8461 (E-mail: kaz-hashi@jikei.ac.jp).

J Thorac Cardiovasc Surg 2006; 132:1465-7

$0022-5223 / \$ 32.00$

Copyright $\odot 2006$ by The American Association for Thoracic Surgery doi:10.1016/j.jtcvs.2006.07.034
}

proved to be a Libman-Sacks vegeta-

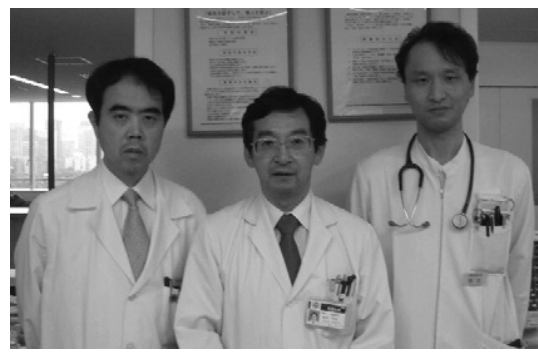

Drs Sakamoto, Hashimoto, and Taguchi (left to right). tion on microscopy.

This is frequently

found in patients with systemic lupus erythematosus (SLE). Unique echocardiographic and intracardiac findings are reported here with the technique of mitral valve plasty.

\section{Clinical Summary}

A 34-year-old woman was admitted after the sudden onset of aphasia associated with mild hemiplegia of her left arm and leg. She had been receiving treatment for SLE for 9 years, but the disease had been inactive, and she had been well, except for numbness in her left hand, at 7 months before this episode. Her medications were an $\mathrm{H}_{2}$ blocker and an oral steroid $(5 \mathrm{mg} / \mathrm{d}$ prednisolone). Admission laboratory tests revealed normal serum chemistry, normal C-reactive protein (CRP) levels, no anemia, and mild thrombocytopenia (the platelet count was $55 \times 10^{3} / \mu \mathrm{L}$ ). 

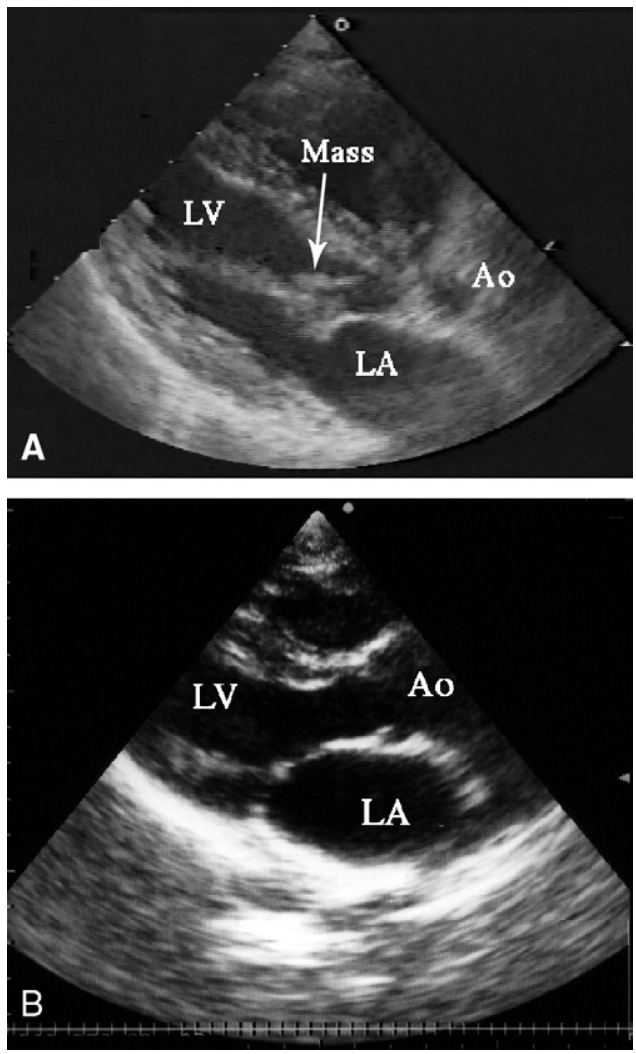

Figure 1. Parasternal long-axis view of echocardiography. A, Vegetation attached to the anterior mitral leaflet and chorda. B, The mitral valve is competent without mitral regurgitation after the operation. Ao, Aorta; $L A$, left atrium; $L V$, left ventricle.

Antinuclear antibody was positive (titer 1:80), but other autoantibodies were normal. Magnetic resonance imaging revealed multiple focal infarcts in the left cerebral hemisphere, pons, and $\mathrm{P} 4$ area corresponding to the territory of the right posterior communicating artery. Two-dimensional transthoracic echocardiography revealed a mobile mass like bunches of grapes $(1.5 \mathrm{~cm}$ in diameter) attached to the A3 area of the anterior mitral leaflet and the chordae of the mitral valve adjacent to the anterior papillary muscle (Figure 1, A). The mitral valve demonstrated normal movement, with no evidence of stenosis or chordal rupture, although trivial regurgitation was detected at the center of the orifice. On the basis of the size and mobility of the tumor, its potential for further systemic embolization was considered to be high, and the patient underwent surgical intervention. At the time of the operation, all intracardiac manipulations were performed through an aortotomy. The mass was first observed by means of endoscopy (Figure 2) and was found to be multifocal in origin, arising from the anterior mitral leaflet, the chordal apparatus, and the septum of the left ventricular outflow tract. The mass was excised as completely as possible, and a few chordae were also removed with it. Intraoperative pathology revealed the typical appearance of a Libman-Sacks vegetation, and it was distinguished from other lesions such as bacterial vegetations, myxoma, or papillary fibroelastoma. The surface of the

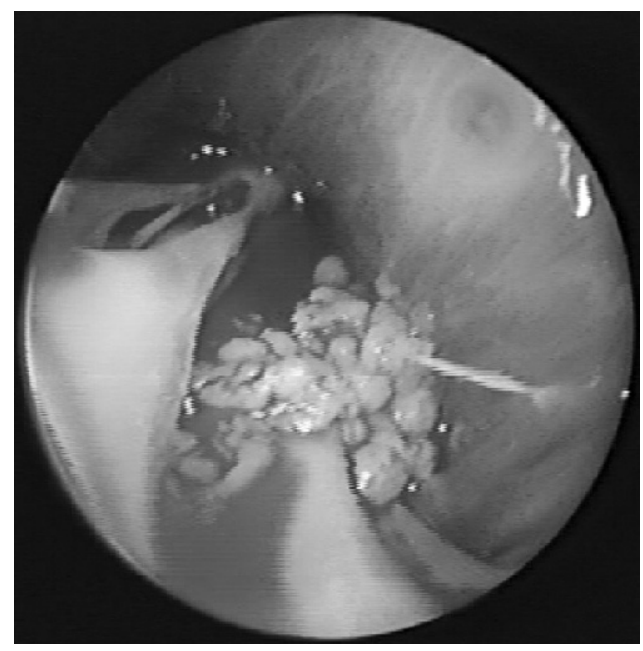

Figure 2. Mass observed with a telescope through the aortotomy.

anterior mitral leaflet that had been attached to the mass was rubbed thoroughly with a sponge, and the involved chordae were resected further. Then the anterior leaflet was supported with 4 artificial polytetrafluoroethylene chordae, ${ }^{*}$ which were placed with the loop technique. ${ }^{1}$ The patient's postoperative course was good (Figure 1, B), and she was discharged 14 days after the operation. The antinuclear antibody titer has been well controlled by means of steroid therapy, and CRP levels remain negative.

\section{Discussion}

Intracardiac masses attached to the mitral valve and chordae are most frequently seen in infective endocarditis. When other features of infective endocarditis, such as fever, an increased white blood cell count, or increase of CRP levels, are not observed at present or in the past, a clinical diagnosis of cardiac tumor is usually made. Tumors arising from valvular tissue are usually considered to be myxomas or papillary fibroelastomas because of their frequency and site of origin. In 20 years' experience of papillary fibroelastomas at the Mayo Clinic, there were 10 lesions arising from the anterior mitral leaflet, papillary muscles, or both in a series of 88 cases. $^{2}$ In patients with SLE, however, Libman-Sacks endocarditis might be strongly suspected, although the frequency of detection by means of echocardiography is lower than the frequency observed at autopsy. Galve and colleagues ${ }^{3}$ reported 7 cases of vegetations detected by means of echocardiography and compatible with Libman-Sacks endocarditis in a series of 74 patients.

Libman-Sacks endocarditis occurs on the aortic and mitral valves or submitral apparatus in most cases, and the affected chordae sometimes undergo rupture. ${ }^{4,5}$ Valve replacement has been the technique of first choice because resection of the mass and valve tissue en bloc will definitely prevent recurrence. In fact, all reports of surgical intervention for Libman-Sacks endocarditis involved valve replacement, as far as we could determine by review. ${ }^{5}$ Libman-Sacks endocarditis is not a neoplasm but represents degeneration caused by

*Gore-Tex chordae, registered trademark of W. L. Gore \& Associates, Inc, Newark, Del 
fibrinoid or inflammatory changes, and therefore appropriate steroid therapy to control SLE is quite important to prevent its recurrence. In other words, mitral valve plasty (particularly in patients without mitral regurgitation) is thought to be an appropriate option if good control of SLE is possible. At 6 months after the operation, our patient showed no evidence of recurrence on echocardiography.

\section{References}

1. von Oppell UO, Mohr FW. Chordal replacement for both minimally invasive and conventional mitral valve surgery using premeasured Gore-tex loops. Ann Thorac Surg. 2000;70:2166-8.
2. Ngaage DL, Mullany CJ, Daly RC, Dearani JA, Edwards WD, Orzulak TA, et al. Surgical treatment of cardiac papillary fibroelastoma: a single center experience with eighty-eight patients. Ann Thorac Surg. 2005; 80:1712-8.

3. Galve E, Candell-Riera J, Pigrau C, Permanyer-Miralda G, Garcia-DelCastillo H, Soler-Soler J. Prevalence, morphologic types and evolution of cardiac valvular disease in systemic lupus erythematosus. $N$ Engl J Med. 1988;319:817-23.

4. Roldan CA. Valvular disease associated with systemic illness. Cardiol Clin. 1998;16:531-50

5. Sasahashi N, Aono N, Kuji T, Shinoka T, Sueshiro M, Tomino T. A case of mitral replacement for Libman-Sacks endocarditis. Nipponn Kyobu Geka Gakkai Zasshi. 1992;40:155-60.

\section{Giant cell aortitis with histopathologic and clinical response to steroid therapy: A case report}

Howard Blumstein, MD, ${ }^{a}$ Leslie Dubin Kerr, MD, a and John T. Fallon, MD, PhD, ${ }^{\mathrm{b}}$ New York, NY

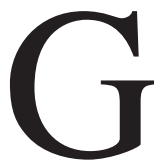

iant cell arteritis (GCA) is a large-vessel vasculitis that affects older individuals and typically presents with constitutional symptoms, polymyalgia, headache, scalp tenderness, jaw claudication, or sudden vision loss.

A subset of patients with GCA can present with large artery disease consisting of aortic aneurysm, dissection, or both. ${ }^{2} \mathrm{We}$ have also recently described our own experience with 19 such patients who underwent surgical repair of aortic aneurysms and who were found to have unsuspected giant cell aortitis on histopathologic review. ${ }^{3}$ This study suggested that large-vessel giant cell aortitis might be a different disease from classic GCA because of its unusual clinical presentation. No conclusions, however, could be drawn regarding the effectiveness of subsequent steroid therapy for this variant of the disease.

A unique opportunity to explore this question arose when a patient with 2 known aortic aneurysms presented. Giant cell aortitis was documented at the repair of the first aneurysm. This patient subsequently lost vision and hearing and regained both after steroid therapy. When the second repair was performed 14 months later, the histopathologic effect of steroid treatment was assessed.

\footnotetext{
From the Department of Medicine, Division of Rheumatology and Department of Pathology and the Cardiovascular Institute, ${ }^{\mathrm{b}}$ Mount Sinai School of Medicine, New York, NY.

Address for reprints: Leslie D. Kerr, MD, Box 1244, Division of Rheumatology, Mount Sinai School of Medicine, 1 Gustave L. Levy Place, New York, NY 10029-6574 (E-mail: leslie.kerr@mssm.edu).

J Thorac Cardiovasc Surg 2006;132:1467-8

$0022-5223 / \$ 32.00$

Copyright $\odot 2006$ by The American Association for Thoracic Surgery doi:10.1016/j.jtcvs.2006.06.043
}

\section{Clinical Summary}

A 67-year-old woman in whom 2 large aneurysms, a thoracic and a thoracoabdominal aneurysm, had been incidentally found on computed tomographic scanning was referred for cardiac catheterization and further management. The catheterization demonstrated severe left main disease, normal left ventricular function, a dilated aortic root with severe aortic insufficiency, and mild narrowing of the right subclavian artery. The patient then underwent a stage I Bentall procedure with osteoplasty of the left main coronary artery. The repair of the thoracoabdominal aneurysm was deferred. On postoperative day 2, she experienced sudden loss of vision in her left eye. The pathology report documented the presence of active giant cell aortitis, and rheumatology consultation was requested. On initial evaluation, the patient denied antecedent symptoms of polymyalgia, headache, scalp tenderness, jaw claudication, joint pains, or constitutional symptoms. She described her vision loss as sudden and accompanied by decreased hearing.

On physical examination, she had no scalp or temporal artery tenderness, and no bruits were appreciated. There was no evidence of synovitis or muscle tenderness. Visual acuity was markedly reduced, and hearing was diminished. Her sedimentation rate was $31 \mathrm{~mm} / \mathrm{h}$ (Westergren). Treatment with highdose intravenous steroids (dexamethasone, $4.5 \mathrm{mg}$ every 12 hours) was begun. Over the next 2 weeks, her vision improved only marginally, and the steroids were then tapered to $5 \mathrm{mg} / \mathrm{d}$. This dose was continued, and at 1 month postoperatively, the patient suddenly regained vision in her left eye and noted restoration of hearing. Prednisone, $5 \mathrm{mg} / \mathrm{d}$, was continued for 6 months and then discontinued. Fourteen months after the initial repair, the patient then underwent repair of the remaining thoracoabdominal aneurysm. This specimen demonstrated severe atherosclerotic changes with mural thrombus; no evidence of discrete aortitis was seen. The patient had an uneventful hospital course and was discharged without steroid therapy. 